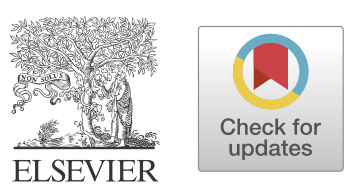

CJC Open 3 (2021) 994-1001

\title{
Original Article \\ Characteristics of Clinicians Are Associated With Their Beliefs About ICD Deactivation: Insight From the DECIDE-HF Study
}

\author{
Florence Landry-Hould, MD, ${ }^{a}$ Blandine Mondésert, MD, ${ }^{a}$ Andrew G. Day, MSc, ${ }^{b}$ \\ Heather J. Ross, MD, MHSc, ${ }^{\mathrm{c}}$ Judith Brouillette, MD, PhD, ${ }^{\mathrm{d}}$ Brian Clarke, MD, ${ }^{\mathrm{e}}$ \\ Shelley Zieroth, MD, ${ }^{\mathrm{f}}$ Mustafa Toma, MD, SM, ${ }^{\mathrm{g}}$ Marie-Claude Parent, MD, ${ }^{\mathrm{a}}$ \\ Robert A. Fowler, MDCM, MSc (Epi), John J. You, MD, MSc, ${ }^{\text {i }}$ and \\ Anique Ducharme, MD, MSc ${ }^{\mathrm{a}}$ on behalf of theDECIDE-HF investigators \\ ${ }^{a}$ Department of Medicine, Montreal Heart Institute, University of Montreal, Montreal, Quebec, Canada \\ ${ }^{b}$ Clinical Evaluation Research Unit, Kingston General Hospital, Kingston, Ontario, Canada \\ ${ }^{c}$ Peter Munk Cardiac Center, University Health Network, University of Toronto, Toronto, Ontario, Canada \\ ${ }^{d}$ Departments of Psychiatry and Addictology, Montreal Heart Institute, University of Montreal, Montreal, Quebec, Canada \\ ${ }^{e}$ Department of Medicine, University of Calgary, Calgary, Alberta, Canada \\ ${ }^{f}$ St Boniface Hospital, University of Manitoba, Winnipeg, Manitoba, Canada \\ ${ }^{g}$ Division of Cardiology, St Paul's Hospital, University of British Columbia, Vancouver, British Columbia, Canada \\ ${ }^{h}$ Department of Medicine and Interdepartmental Division of Critical Care Medicine, University of Toronto, Toronto, Ontario, Canada \\ ${ }^{i}$ Department of Medicine, Division of General Internal and Hospitalist Medicine, Trillium Health Partners, Mississauga, Ontario, Canada
}

\begin{abstract}
Background: Discussing goals of care with heart failure patients is recommended but is not done systematically, due to factors such as time and personal beliefs. A recent survey showed that onefifth of clinicians believe that implantable cardioverter defibrillator deactivation (ICDD) is unethical or constitutes physician-assisted suicide. We investigated whether individuals' characteristics are associated with these beliefs.

Methods: The Decision-Making About Goals of Care for Hospitalized Patients With Heart Failure (DECIDE-HF) survey was given to healthcare providers at 9 hospitals to assess their perceived barriers to
\end{abstract}

Advances in pharmacologic and device therapies, such as use of implantable cardioverter defibrillators (ICDs), have dramatically improved survival in patients with heart failure (HF). ${ }^{1}$ Given that ICDs are indicated for primary or secondary prevention of ventricular arrhythmia and/or sudden cardiac death, ${ }^{2}$ their utility at end-of-life care is debatable. Inappropriate and even appropriate shock deliveries can cause pain, reduced quality of life, ${ }^{3}$ and

Received for publication January 26, 2021. Accepted March 9, 2021.

Ethics Statement: All local institutional review boards approved the proto$\mathrm{col}$, and participants provided written consent. This study was conducted in compliance with the Canadian Privacy Legislation and the revised (2013) Declaration of Helsinki.

Corresponding authors: Dr Anique Ducharme, Department of Medicine, Montreal Heart Institute, 5000, Belanger East, Montreal, Quebec H1T1C8,

\section{RÉSUMÉ}

Contexte : Une discussion sur les objectifs de soins avec les patients atteints d'insuffisance cardiaque est recommandée, mais elle n'est pas systématiquement menée en raison de facteurs tels que les contraintes de temps et les croyances personnelles. Selon une enquête récente, un cinquième des cliniciens croient qu'une désactivation d'un défibrillateur cardioverteur implantable (DDCl) est contraire à l'éthique ou représente un suicide assisté par le médecin. Nous avons vérifié si des caractéristiques individuelles sont associées à ces croyances.

Méthodologie : L'enquête DECIDE-HF (Decision-Making About Goals of Care for Hospitalized Patients With Heart Failure) a été réalisée chez

even prolonged suffering, ${ }^{4}$ as the metabolic changes occurring at the very end of life increase susceptibility to receiving shocks deemed appropriate by the device. ${ }^{5}$ Although most patients find the administration of shocks uncomfortable and distressing, 5,6 almost one-fourth of those with a do-not-resuscitate order have received ICD shocks in their last 24 hours of life. ${ }^{7}$ Further, very few clinicians discuss the eventual possibility of ICD deactivation

Canada. Tel.: +1-514-376-3330, ext 3927; fax: +1-514-593-2575

E-mail: anique.ducharme@umontreal.ca

Dr Blandine Montdésert, Department of Medicine, Montreal Heart Institute, 5000, Belanger East, Montreal, Quebec H1T1C8, Canada. Tel.: +1-514376-3330, ext. 3615; fax: +1-514-593-2575.

E-mail: blandine.mondesert@umontreal.ca

See page 1000 for disclosure information. 
goals-of-care discussions. The association between respondent characteristics and their beliefs was examined using 2 adjusted logistic regression models.

Results: We included 760 clinicians (459 nurses, 94 fellows, and 207 cardiologists). The responses varied among professions, with the belief that ICDD is unethical considered to be important barrier by nurses $(24 \%)$, fellows $(10 \%)$, and staff $(7 \%) ; P<0.001)$. After adjusting for site, spirituality being more important in life (odds ratio [OR]: 2.21; 95\% confidence interval [Cl]:1.37-3.56; $P=0.001$, compared to less important), region of training (Asia [OR: 5.88; 95\% Cl: 2.12-16.31; $P=0.001$ ] and Middle East [OR: 5.55; 95\% Cl:1.57-19.63; $P=0.008$ ] compared to Canada), and years in practice (OR: $1.32 ; 95 \% \mathrm{Cl}: 1.07-1.63 ; P=0.01$ per decade) influenced beliefs about ICDD being unethical, with similar results for the belief that ICDD represents physician-assisted suicide.

Conclusions: Sociocultural factors, region of training, and profession influence clinicians' beliefs about ICDD being unethical and representing physician-assisted suicide. These factors and beliefs must be acknowledged when facing the delicate issue of end-oflife discussion.
(ICDD), either before implantation or at the time of battery replacement, and then when the time comes at end of life, less than half of terminally ill patients were given the option to turn it off, ${ }^{8}$ with some having never even been informed of this possibility.

Accordingly, routine implantation of ICDs raises the issue of possible deactivation once the goals of care have switched toward providing comfort. Several ethical analyses regarding ICDD have shown that it should not foster new moral issues. ${ }^{9-12}$ Although withholding vs withdrawing therapies may appear to be equivalent ethically, ${ }^{13}$ their psychological impacts may be viewed as different by some healthcare professionals and patients, ${ }^{9,14}$ as shown in a qualitative patient focus group. ${ }^{5}$ Patients viewed device deactivation as something special, ${ }^{15}$ and this possibility was discussed with the professionals only very infrequently. ${ }^{16}$

A recent survey of healthcare professionals on what they perceive to be barriers to their engagement in end-of-life discussion with hospitalized HF patients showed that the most important perceived barriers were family member or patient difficulty accepting a poor prognosis, lack of understanding about the limitations and harms of life-sustaining treatments, and lack of agreement among family members about goals of care. ${ }^{17}$ In addition, we found that one-fifth of the respondents considered ICDD to be unethical and/or to represent assisted suicide, while clinician characteristics explained only $3 \%$ of the variance overall. ${ }^{17}$ Our aim here was to explore the individual characteristics of these clinicians, postulating that some might be associated with these beliefs about barriers to end-of-life discussion.

\section{Methods}

Decision-Making About Goals of Care for Hospitalized Patients With Heart Failure (DECIDE-HF) was a survey of healthcare providers (cardiology nurses, fellows, and staff) from 9 des professionnels de la santé de neuf hôpitaux dans le but d'évaluer les obstacles qu'ils percevaient face à la discussion sur les objectifs de soins. Le lien entre les caractéristiques des répondants et leurs croyances a été analysé à l'aide de deux modèles ajustés de régression logistique.

Résultats : Nous avons interrogé 760 cliniciens (459 infirmières, 94 médecins associés et 207 cardiologues). Les réponses ont varié d'une profession à l'autre, la croyance qu'une DDCl est contraire à l'éthique étant considérée comme un obstacle important par $24 \%$ des infirmières, $10 \%$ des médecins associés et $7 \%$ des membres du personnel $(p<0,001)$. Après ajustement selon l'établissement, l'importance de la spiritualité dans la vie (très important [rapport de cotes $\{R C\}]=2,21$; intervalle de confiance [IC] à $95 \%: 1,37-3,56$; $p=0,001$ comparativement à moins important), la région d'obtention du diplôme (Asie [RC = 5,88; IC à $95 \%: 2,12-16,31 ; p=0,001$ ] et Moyen-Orient $[\mathrm{RC}=5,55$; IC à $95 \%: 1,57-19,63 ; p=0,008]$ comparativement au Canada) et le nombre d'années d'exercice ( $R C=1,32$; IC à $95 \%: 1,07-1,63 ; p=0,01$ par tranche de 10 ans) ont influencé les croyances voulant qu'une $\mathrm{DDCl}$ soit contraire à l'éthique, et les résultats ont été similaires pour la croyance selon laquelle une DDCI représente un suicide assisté par le médecin.

Conclusions : Des facteurs socioculturels, la région de formation et la profession influencent les croyances des cliniciens sur la DDCl et le fait qu'ils la considèrent comme étant une démarche contraire à l'éthique ou un suicide assisté par un médecin. Ces facteurs et croyances doivent être reconnus lorsque vient le temps d'aborder la délicate question de la discussion sur la fin de vie.

Canadian teaching hospitals conducted to identify barriers to goals-of-care conversations with hospitalized HF patients. It provided insight about clinician perspectives, as well as a ranking of the important barriers. The questionnaires were returned by 770 of $1024(75.2 \%)$ of the eligible clinicians, and the results have been published previously. ${ }^{17}$ We found that almost $20 \%$ of respondents viewed ICDD as being unethical (outcome 1) or as constituting physician-assisted suicide (outcome 2 ). The present analysis focuses on these 2 barriers. The specific questions examined by the survey related to this analysis can be found in Supplemental Appendix S1. Responses were graded using a Likert scale, with 1 being extremely unimportant, and 7 being extremely important. For the present analysis, we dichotomized a priori the outcomes as important (7-extremely important; 6-very important; or 5-somewhat important) vs unimportant (4-neither important nor unimportant; 3-somewhat unimportant; 2-very unimportant; and 1 - extremely unimportant).

The following variables were included in this analysis: age; sex; profession; experience; site; ethnicity; religious background; the importance of spirituality in the respondent's life; region of training. Two multivariate models were used to determine the independent association of these characteristics with each of the 2 outcomes.

\section{Statistical analysis}

Raw agreement and Kappa's chance corrected agreement between the 2 dichotomized outcomes were reported, and the proportion who responded important in each profession was reported for both outcomes. The distribution of respondent characteristics was compared between respondents who answered that the barriers were important vs unimportant. Categorical characteristics are reported as counts and percentages and compared using the $\chi^{2}$ test. As some categories were 
sparse, we verified the $P$ values obtained by the $\chi^{2}$ test by estimating exact $P$ values using a Monte Carlo simulation based on 10,000 random simulations under the null hypothesis of no association. The Mantel-Haenszel test was used to stratify categorical characteristics by profession, and the stratified Wilcoxon rank sum (Van Elteren) test, weighted by the stratum size, was used for continuous characteristics.

For both outcomes, separate logistic regression models were tested. We first modelled each characteristic separately in a series of unadjusted single predictor models. For categorical variables with more than 2 categories, we estimated odds ratios (ORs) with $95 \%$ confidence intervals (CIs) for each category vs the referent category. $P$ values for each category vs the referent were provided, as well as an overall $P$ value for the given variable. We then used backwards, stepwise selection with an entry and retention criteria of $P<0.15$ to select variables for inclusion in a multivariable model. The single predictor and the first model treated site as a fixed effect, but the multivariable modelling was repeated, treating site as a random effect as estimated by a generalized linear mixed-effects model with a logit link and binomial response distribution. SAS version 9.4 (SAS Institute Inc., Cary, NC) was used. No correction was used for multiplicity of tests, and no imputation was made for missing data.

All local institutional review boards approved the protocol, and participants provided written consent. This study was conducted in compliance with Canadian Privacy Legislation and the revised (2013) Declaration of Helsinki.

\section{Results}

From DECIDE-HF, 760 respondents answered the questions of interest and constitute our study population: 459 nurses, 94 fellows, and 207 staff cardiologists.

\section{ICDD is unethical}

The characteristics of the whole population and the subgroup of participants who felt that ICDD is unethical are shown in Table 1 and Figure 1. By univariate analysis, sex, ethnicity, profession, location of training, importance of spirituality, and site were statistically associated with this belief. We then constructed profession-specific analyses, and found that sex was no longer independently associated with ICDD being perceived as unethical, whereas having been in practice for fewer years became significant $(P=0.023)$.

Table 2 provides the results of logistic regression, with the dependent variable ICDD is unethical being an important barrier to discussing goals of care. By multivariate analysis, sites and region of training (Asia [OR 5.88, 95\% CI 2.12-16.31, $P=0.001]$, Middle East [OR 5.55, 95\% CI 1.57-19.63, $P=0.008]$ and other [OR 5.24, 95\% CI 1.89-14.51, $P=0.001])$ remained significant. In addition, profession was significant, with $24 \%$ of the nurses $(\mathrm{OR}=5.04,95 \%$ CI 2.17 $11.71, P<0.001)$ believing that ICDD is unethical, compared to $10 \%$ of the fellows and $7 \%$ of the cardiologists $(P<0.001)$, as was the importance of spirituality $(P<0.004)$. Participants reporting a Likert-scale rating of 5-7 for "importance of spirituality/religion" were twice as likely to consider ICDD unethical as were respondents reporting "less importance of spirituality/religion" (Likert-scale rating of $1-4 ; \mathrm{OR}=1.96,95 \%$ CI $1.24-$
3.10). The generalized mixed-effects model showed similar results (data not shown).

\section{ICDD represents physician-assisted suicide}

Supplemental Tables S1 and S2 indicates that results for the belief that ICDD represents physician-assisted suicide were similar to those for the ICDD is unethical outcome. The correlation and agreement between the responses to the 2 barriers were very high $($ Spearman $=0.88$, Kappa $=0.88 ; 95 \% \mathrm{CI}$ $0.85-0.91)$.

\section{Discussion}

We showed that clinician characteristics are associated with their beliefs about ICDD being unethical or representing physician-assisted suicide. Awareness of these barriers is important, as they may create additional challenges in discussing goals of care with patients hospitalized with HF. We found that profession (nurse, fellow, or cardiologist), ethnicity, region of training, sites, and importance of spirituality were all significantly associated with these specific beliefs. These individual factors appeared to be more important than patientrelated factors (age, sex, previous discussion, HF severity, comorbidities, number of admissions, number of shocks, treatment intent, and social support), which explained only $10 \%$ of the likelihood of and $1 \%$ of clinician confidence in discussing ICDD, in a previous report. ${ }^{18}$

\section{Type of professionals}

The effect of profession was striking, with nurses and fellows being respectively 5.04 and 2.23 times more likely to believe that ICDD is unethical, compared to staff. The finding that fellows tend to be more likely than staff to have this belief has been previously reported. ${ }^{19}$ This belief might be explained by both the clinical skills of nurses and fellows and the concept of experiential learning in ethical dilemmas-those with prior ethics education are more comfortable discussing withholding of life-prolonging treatment, with fellows feeling more competent than medical students, ${ }^{20}$ who consider themselves inadequately trained to engage in such discussions. ${ }^{21}$ Finally, nurses and fellows may carry an idealistic view of ICDs, overestimating the expected benefit (ie, survival) and minimizing the inconveniences (ie, lead failure, inappropriate shocks), especially early in their career when they have not yet witnessed shock deliveries, with the attendant discomfort ${ }^{3}$ and sometimes prolonged suffering. ${ }^{4}$ On the other hand, nurses may be in a privileged position to discuss these issues, per their focus on symptom control, knowledge of palliative care, and close proximity to the patient. ${ }^{18,22}$ Yet, they feel this discussion should be initiated by a physician, who they believe is a better judge of $\operatorname{prognosis}^{17}$; likewise, nurses in palliative oncology described themselves as being in a difficult position, trapped between the patient and the physician. $^{23}$ Furthermore, Kramer and colleagues reported the uncomfortable feelings of nurses regarding their involvement in ICDD discussion, and their impression of actively ending the patient's life instead of waiting for the so-called natural evolution of the disease. ${ }^{24}$ As a consequence, specialist nurses are less involved in ICDD 
Table 1. Participant characteristics by belief that implantable cardioverter defibrillator deactivation is unethical being an important barrier to end-oflife discussions

\begin{tabular}{|c|c|c|c|}
\hline Characteristic & $\begin{array}{c}\text { All } \\
\mathrm{n}=760\end{array}$ & $\begin{array}{l}\text { Important barrier } \\
\qquad \mathrm{n}=132\end{array}$ & $\begin{array}{l}\text { Not an important barrier } \\
n \mathrm{n}=628\end{array}$ \\
\hline Age, y & $\begin{array}{c}\mathrm{n}=716 \\
40.4 \pm 11.4 \\
(21.0-74.0)\end{array}$ & $\begin{array}{c}\mathrm{n}=124 \\
40.9 \pm 11.9 \\
23.0-74.0\end{array}$ & $\begin{array}{c}\mathrm{n}=592 \\
40.4 \pm 11.3 \\
(21.0-74.0)\end{array}$ \\
\hline \multicolumn{4}{|l|}{ Sex } \\
\hline Missing & $24(3.2)$ & $6(4.5)$ & $18(2.9)$ \\
\hline Male & $273(35.9)$ & $26(19.7)$ & $247(39.3)$ \\
\hline Female & $463(60.9)$ & $100(75.8)$ & $363(57.8)$ \\
\hline \multicolumn{4}{|l|}{ Profession } \\
\hline Nurse & $459(60.4)$ & $109(82.6)$ & $350(55.7)$ \\
\hline Fellow & $94(12.4)$ & $9(6.8)$ & $85(13.5)$ \\
\hline Staff member & $207(27.2)$ & $14(10.6)$ & $193(30.7)$ \\
\hline \multicolumn{4}{|l|}{ Ethnicity } \\
\hline Missing & $39(5.1)$ & $9(6.8)$ & $30(4.8)$ \\
\hline Other & $15(2.0)$ & $2(1.5)$ & $13(2.1)$ \\
\hline White & $518(68.2)$ & $76(57.6)$ & $442(70.4)$ \\
\hline South Asian & $14(1.8)$ & $8(6.1)$ & $6(1.0)$ \\
\hline Chinese & $36(4.7)$ & $2(1.5)$ & $34(5.4)$ \\
\hline Black & $17(2.2)$ & $6(4.5)$ & $11(1.8)$ \\
\hline Filipino & $30(3.9)$ & $15(11.4)$ & $15(2.4)$ \\
\hline Latin American & $12(1.6)$ & $3(2.3)$ & $9(1.4)$ \\
\hline Arab & $27(3.6)$ & $5(3.8)$ & $22(3.5)$ \\
\hline Southeast Asian & $44(5.8)$ & $3(2.3)$ & $41(6.5)$ \\
\hline West Asian & $2(0.3)$ & $1(0.8)$ & $1(0.2)$ \\
\hline Korean & $6(0.8)$ & $2(1.5)$ & $4(0.6)$ \\
\hline \multicolumn{4}{|l|}{ Religion } \\
\hline Missing & $35(4.6)$ & $9(6.8)$ & $26(4.1)$ \\
\hline Other & $39(5.1)$ & $9(6.8)$ & $30(4.8)$ \\
\hline Roman Catholic & $257(33.8)$ & $52(39.4)$ & $205(32.6)$ \\
\hline Protestant Christian & $89(11.7)$ & $17(12.9)$ & $72(11.5)$ \\
\hline Orthodox Christian & $23(3.0)$ & $4(3.0)$ & $19(3.0)$ \\
\hline Other Christian & $24(3.2)$ & $7(5.3)$ & $17(2.7)$ \\
\hline Muslim & $39(5.1)$ & $7(5.3)$ & $32(5.1)$ \\
\hline Jewish & $20(2.6)$ & $3(2.3)$ & $17(2.7)$ \\
\hline Buddhist & $11(1.4)$ & $2(1.5)$ & $9(1.4)$ \\
\hline Hindu & $12(1.6)$ & $1(0.8)$ & $11(1.8)$ \\
\hline Sikh & $6(0.8)$ & $1(0.8)$ & $5(0.8)$ \\
\hline No affiliation & $205(27.0)$ & $20(15.2)$ & $185(29.5)$ \\
\hline \multicolumn{4}{|l|}{ Location of training } \\
\hline Missing & $23(3.0)$ & $6(4.5)$ & $17(2.7)$ \\
\hline Other & $7(0.9)$ & $5(3.8)$ & $2(0.3)$ \\
\hline Canada & $623(82.0)$ & $95(72.0)$ & $528(84.1)$ \\
\hline United States & $11(1.4)$ & $2(1.5)$ & $9(1.4)$ \\
\hline UK/Ireland/Australia/New Zealand & $18(2.4)$ & $0(0.0)$ & $18(2.9)$ \\
\hline Europe & $28(3.7)$ & $4(3.0)$ & $24(3.8)$ \\
\hline Asia & $21(2.8)$ & $11(8.3)$ & $10(1.6)$ \\
\hline Middle East & $15(2.0)$ & $5(3.8)$ & $10(1.6)$ \\
\hline Central or South America & $8(1.1)$ & $1(0.8)$ & $7(1.1)$ \\
\hline Africa & $6(0.8)$ & $3(2.3)$ & $3(0.5)$ \\
\hline \multirow[t]{3}{*}{ Years of practice } & $\mathrm{n}=731$ & $\mathrm{n}=125$ & $\mathrm{n}=606$ \\
\hline & $14.5 \pm 11.1$ & $15.3 \pm 12.3$ & $14.3 \pm 10.9$ \\
\hline & $(0.0-52.0)$ & $(0.0-50.0)$ & $(1.0-52.0)$ \\
\hline Importance of spirituality & $\mathrm{n}=736$ & $\mathrm{n}=126$ & $\mathrm{~N}=610$ \\
\hline & $4.4 \pm 1.8$ & $4.9 \pm 1.8$ & $4.3 \pm 1.8$ \\
\hline & $(1.0-7.0)$ & $(1.0-7.0)$ & $(1.0-7.0)$ \\
\hline \multicolumn{4}{|l|}{ Site } \\
\hline 1 & $158(20.8)$ & $23(17.4)$ & $135(21.5)$ \\
\hline 2 & 75 (9.9) & $8(6.1)$ & $67(10.7)$ \\
\hline 3 & $91(12.0)$ & $20(15.2)$ & $71(11.3)$ \\
\hline 4 & $94(12.4)$ & $12(9.1)$ & $82(13.1)$ \\
\hline 5 & $63(8.3)$ & 17 (12.9) & $46(7.3)$ \\
\hline 6 & $63(8.3)$ & $17(12.9)$ & $46(7.3)$ \\
\hline 7 & $78(10.3)$ & $9(6.8)$ & $69(11.0)$ \\
\hline 8 & $72(9.5)$ & $12(9.1)$ & $60(9.6)$ \\
\hline 9 & $66(8.7)$ & $14(10.6)$ & $52(8.3)$ \\
\hline
\end{tabular}

Values are reported as $\mathrm{n}(\%)$ or mean \pm standard deviation (min-max). The $\mathrm{n}$ reported for the continuous variables is lower than the $\mathrm{n}$ for the column, due to missing data. 
Table 2. Logistic regression results for the belief implantable cardioverter defibrillator deactivation is unethical being an important barrier to end-oflife discussions, by individuals' characteristics

\begin{tabular}{|c|c|c|c|c|c|}
\hline & $\mathrm{N}^{*}$ & Unadjusted $\mathrm{OR}^{\dagger}(95 \% \mathrm{CI})$ & $P$ value & Adjusted $\mathrm{OR}^{\ddagger}(95 \% \mathrm{CI})$ & $P$ value \\
\hline Age (per decade) & 716 & $1.04(0.88-1.24)$ & 0.625 & \multicolumn{2}{|c|}{ Not selected at $P<0.15$} \\
\hline Sex (female vs male) & 736 & $2.62(1.65-4.15)$ & $<0.001$ & $1.65(0.85-3.21)$ & 0.141 \\
\hline Ethnicity (vs white) & 721 & & 0.069 & \multicolumn{2}{|c|}{ Not selected at $P<0.15$} \\
\hline Arab & 27 & $1.32(0.49-3.60)$ & 0.585 & & \\
\hline Asian & 132 & $1.79(1.12-2.86)$ & 0.016 & & \\
\hline Black & 17 & $3.17(1.14-8.83)$ & 0.027 & & \\
\hline Latin American & 12 & $1.94(0.51-7.32)$ & 0.329 & & \\
\hline Other & 15 & $0.89(0.20-4.04)$ & 0.885 & & \\
\hline White & 518 & \multicolumn{2}{|c|}{ Referent } & \multicolumn{2}{|l|}{ Referent } \\
\hline Occupation (vs staff) & 760 & & $<0.001$ & & 0.001 \\
\hline Fellow & 94 & $1.46(0.61-3.50)$ & 0.397 & $2.23(0.75-6.64)$ & 0.151 \\
\hline Nurse & 459 & $4.29(2.40-7.70)$ & $<0.001$ & $5.04(2.17-11.71)$ & $<0.001$ \\
\hline Staff & 207 & \multicolumn{2}{|c|}{ Referent } & \multicolumn{2}{|l|}{ Referent } \\
\hline Region of training (vs Canada) & 737 & & $<0.001$ & & $<0.001$ \\
\hline Asia & 21 & $6.11(2.53-14.79)$ & $<0.001$ & $5.88(2.12-16.31)$ & 0.001 \\
\hline Middle East & 15 & $2.78(0.93-8.31)$ & 0.068 & $5.55(1.57-19.63)$ & 0.008 \\
\hline Europe/Australia/New Zealand & 46 & $0.53(0.19-1.51)$ & 0.234 & $0.48(0.15-1.54)$ & 0.217 \\
\hline United States & 11 & $1.24(0.26-5.81)$ & 0.789 & $1.43(0.27-7.53)$ & 0.672 \\
\hline Other & 21 & $4.17(1.71-10.17)$ & 0.002 & $5.24(1.89-14.51)$ & 0.001 \\
\hline Canada & 623 & \multicolumn{2}{|c|}{ Referent } & \multicolumn{2}{|l|}{ Referent } \\
\hline Years in practice (per decade) & 731 & $1.09(0.92-1.29)$ & 0.345 & $1.32(1.07-1.63)$ & 0.010 \\
\hline Religious background (vs no affiliation) & 725 & & 0.005 & \multicolumn{2}{|c|}{ Not selected at $P<0.15$} \\
\hline Christian & 393 & $2.36(1.40-3.99)$ & 0.001 & & \\
\hline Other & 127 & $2.05(1.07-3.90)$ & 0.030 & & \\
\hline No affiliation & 205 & \multicolumn{2}{|c|}{ Referent } & \multicolumn{2}{|l|}{ Referent } \\
\hline $\begin{array}{r}\text { Importance of spirituality/religion in your } \\
\text { life (very or extremely important vs less) }\end{array}$ & 736 & $2.23(1.50-3.31)$ & $<0.001$ & $2.21(1.37-3.56)$ & 0.001 \\
\hline Site (vs 1) & 760 & & 0.042 & & 0.003 \\
\hline 2 & 75 & $0.70(0.30-1.65)$ & 0.426 & $1.07(0.40-2.82)$ & 0.895 \\
\hline 3 & 91 & $1.65(0.85-3.21)$ & 0.138 & $3.35(1.53-7.34)$ & 0.003 \\
\hline 4 & 94 & $0.86(0.41-1.82)$ & 0.691 & $1.06(0.46-2.43)$ & 0.896 \\
\hline 5 & 63 & $2.17(1.07-4.12)$ & 0.033 & $3.54(1.49-8.40)$ & 0.004 \\
\hline 6 & 63 & $2.17(1.07-4.42)$ & 0.033 & $3.41(1.49-7.84)$ & 0.004 \\
\hline 7 & 78 & $0.77(0.34-1.74)$ & 0.525 & $0.96(0.38-2.44)$ & 0.936 \\
\hline 8 & 72 & $1.17(0.55-2.51)$ & 0.680 & $1.07(0.45-2.56)$ & 0.882 \\
\hline 9 & 66 & $1.58(0.76-3.30)$ & 0.224 & $1.57(0.66-3.74)$ & 0.306 \\
\hline 1 & 158 & \multicolumn{2}{|c|}{ Referent } & \multicolumn{2}{|l|}{ Referent } \\
\hline
\end{tabular}

The Hosmer-Lemeshow test for age and years of practice from the single predictor models (ie, unadjusted) were both $P>0.2$, justify modelling them as linear. The Hosmer-Lemeshow test for the selected multi-predictor model was $P=0.094$.

CI, confidence interval; OR, odds ratio.

${ }^{*}$ Number of nonmissing values in the analysis.

${ }^{\dagger}$ Each predictor was modelled separately without adjustment for other variables.

${ }^{\ddagger}$ This model included predictors that were selected with $P<0.15$ using backward stepwise selection. This model treated site as a fixed effect using regular multiple logistic regression. However, results were very similar when site was treated as a random effect using a generalized linear mixed-effects model.

discussion than they probably should be, at least partly because of the medical hierarchy. ${ }^{18}$

\section{Region of training and ethnicity}

Only a minority of professionals trained in North America and Europe had the beliefs that ICDD is unethical or represents physician-assisted suicide, which had a greater likelihood of occurring for those trained in Asia or the Middle East. Our results are similar to those of Hill and colleagues, ${ }^{18}$ who showed that US healthcare professionals are more confident about their decisions, having fewer ethical and legal concerns regarding palliative care issues than their European counterparts, ${ }^{18}$ despite similar national recommendations regarding ICDD. ${ }^{25}$.

Likewise, ethnicity was associated with the belief that ICDD represents physician-assisted suicide, with professionals from Asian countries being more likely to have this belief. Ethnicity is a complex factor that encompasses not only region, but also religion, family issues, legislation, economic status, personal attitude, and consequently various beliefs on end-of-life care within a geographic area. ${ }^{27}$ Phua and colleagues ${ }^{27}$ tried to explain the attitudes about end-of-life care held in Asian societies, wherein there is no unified approach, given the differences in societal culture among such countries. Nevertheless, he showed that a majority of Asian healthcare providers $(74.5 \%)$ perceived ethical differences between withholding (not offering a treatment) and withdrawing (removing a device or a support) therapies in terminally ill patients and therefore were more likely to be aggressive in application of organ-supporting care at the end of life, in comparison to their American and European colleagues. ${ }^{27}$ Understanding the ethnic background of each member of the multidisciplinary team may be helpful to 


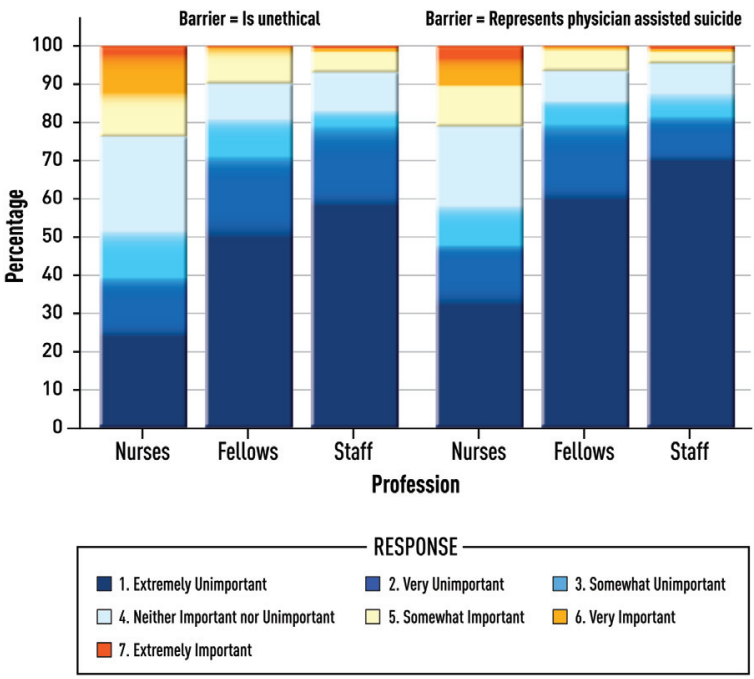

Figure 1. Beliefs about implantable cardioverter defibrillator deactivation (ICDD), by profession. Distribution of the responses to "ICDD is unethical" (left) and "ICDD represents physician-assisted suicide" (right), by profession. The response distributions of both barriers were significantly different between professions (both $P<0.001$ ).

locally implement end-of-life care programs that respect individual beliefs.

\section{Religion and importance of spirituality in life}

Although we found no association with a specific religious affiliation, spirituality was an important variable. Respondents with a high level of spirituality had twice the likelihood of having the belief that ICDD was unethical. This suggests that the place of spirituality in healthcare professionals' lives may influence their medical decisions. ${ }^{28}$ In contrast, Voorheesa showed that professionals with important religious convictions or spirituality were more likely to discuss prognosis with terminally ill cancer patients because of their values and the importance given to communication. ${ }^{29}$ One potential explanation of this apparent discrepancy might lie in the unpredictable trajectory of HF patients, compared to those in oncology, who have periods of stability followed by deterioration and uncertainty about prognosis. ${ }^{30}$ Nevertheless, this trajectory should remind us that a hospital admission for acute HF decompensation or even for ICD shocks, whether appropriate or inappropriate, is a marker of worse prognosis. ${ }^{31,32}$ This vulnerable phase could be an opportunity to reexamine the patient's goals for care and advance directives, including discussion about ICDD. Preliminary discussion should ideally occur before implantation and at the time of consideration for battery replacement. ${ }^{33}$ This discussion might be particularly important for a family with cultural and religious reasons for declining ICDD, as they may believe that ICDD accelerates death. ${ }^{33}$

\section{The ethics of ICDD}

Almost one-fifth of our respondents were apprehensive regarding the ethics of ICDD. Although we cannot determine whether these beliefs actually impede their delivery of care, it seems important to reconcile healthcare providers' personal perceived barriers to discussion and their obligation to advanced HF patients to provide fair evidence for informed consent regarding ICDD. ${ }^{15,28}$ An educational program clarifying the ethical and/or legal aspects of ICDD might be of value-one that considers the intention behind the intervention, which is to avoid a futile and potentially harmful treatment by ICD, by letting the patient die from the terminal disease itself; by contrast, euthanasia results directly in the patient's death. ${ }^{28}$ Also, distinguishing between the types of treatment might be helpful. Although a patient can request that any treatment be stopped at any time (such as ICD or ventilator support, which are outside the individual's body and can easily be turned off), ${ }^{9,15}$ they cannot ask to have undone what has become an integral part of their bodies (eg, a cardiac transplant). ${ }^{15}$ These subtleties could be integrated into continuous professional development programs, to create a collaborative effort within the multidisciplinary team to engage in end-of-life discussions with advanced HF patients. ${ }^{18}$ A short standardized educational program has recently shown benefits, increasing both the rate of ICDD discussion and ICDD. ${ }^{34}$ Future research needs to examine optimal training methods in patient-centred communication, with a focus on addressing the barriers identified by both patients and clinicians. Also important for future research is to consider clinicians' training pathways and cultural differences when designing and implementing training in providing patientcentred care and prognosis. ${ }^{35}$

\section{Limitations}

We included healthcare professionals from academic centres with onsite electrophysiology services; thus, our results might not be generalizable to community hospitals, where arrhythmic storms and complex arrhythmias might be less frequent. Differences among professionals may be greater in community hospitals, owing to lower levels of exposure and knowledge about ICDD. Furthermore, only specific characteristics were studied; consequently, we cannot exclude the possibility that other factors may influence professionals' beliefs. In addition, our sample size was relatively small for some subgroups, and despite having an excellent correlation among respondents for 2 barriers, some results did not reach statistical significance.

\section{Conclusion}

Decision-making regarding ICDD is complex and requires a multidisciplinary approach that respects differences in the baseline perceptions of clinicians. We found that the characteristics of healthcare professionals that are associated with the beliefs that ICDD is unethical or represents physician-assisted suicide include profession, location of training, ethnicity, and the importance of spirituality in their life, with nurses and fellows being more likely to have these as barriers to discussion with patients, compared to staff physicians. These variations in beliefs suggest that further discussion is warranted, taking into consideration sociocultural issues and interprofessional differences. Knowledge of these ethical issues should be integrated, or reinforced, in the respective academic paths of medical trainees, fellows, and nurses, and regularly discussed in continued medical education meetings; these 
should include not only explanations about ICD's indication and function, but also information regarding legal and ethical issues on ICD implantation and deactivation. Finally, it is essential to acknowledge that personal characteristics do influence thoughts about ICDD, so that cardiology healthcare workers can stay attentive to their own beliefs and consider first and foremost the well-being of the patient.

\section{Funding Sources}

This study was funded by the Heart and Stroke Foundation, Ontario Provincial Office (\#BR7515), Toronto, Ontario, Canada. Dr Ducharme holds the Fondation Marcelle et Jean Coutu, Cal et Janine Moisan University of Montreal chair for best practices in advanced heart failure.

\section{Disclosures}

The authors have no conflicts of interest to disclose.

\section{References}

1. Sherazi S, Mcnitt S, Aktas MK, et al. End-of-life care in patients with implantable cardioverter defibrillators: a MADIT-II substudy. Pacing Clin Electrophysiol 2013;36:1273-9.

2. Bennett M, Parkash R, Nery P, et al. Canadian Cardiovascular Society/ Canadian Heart Rhythm Society 2016 implantable cardioverter defibrillator guidelines. Can J Cardiol 2017;33:174-88.

3. Romanò M, Gorni G. Implantable cardiac device deactivation at the end of life. G Ital Cardiol (Rome) 2020;21:286-95.

4. Westerdahl AK, Frykmana V. Defibrillator patients should not be denied a peaceful death. Int J Cardiol 2015;182:440-6.

5. Goldstein NE, Siddiqui S, Teitelbaum E, et al. That's like an act of suicide" patients' attitudes toward deactivation of implantable defibrillators. J Gen Intern Med 2007;23:7-12.

6. Ahmad MBL, Roelke M, Bernstein AD, Parsonnet V. Patients' attitudes toward implanted defibrillator shocks. Pacing Clin Electrophysiol 2006;23:934-8.

7. Kinch Westerdahl A, Sjöblom J, Mattiasson AC, Rosenqvist M, Frykman V. Implantable cardioverter-defibrillator therapy before death: high risk for painful shocks at end of life. Circulation 2014;129:422-9.

8. Hill L, Dixon L, Cole BR, Moser DK, Fitzsimons D. Implantable cardioverter defibrillator (ICD) deactivation discussions: reality versus recommendations. Eur J Cardiovasc Nurs 2016;15:20-9.

9. Sulmasy DP. Within you/without you: biotechnology, ontology, and ethics. J Gen Intern Med 2008;23(suppl 1):S69-72.

10. Kelley AS, Reid MC, Miller DH, Fins JJ, Lachs MS. Implantable cardioverter-defibrillator deactivation at the end of life: a physician survey. Am Heart J 2009;157:702-8.

11. Pasalic D, Gazelka HM, Topazian RJ, et al. Palliative care consultation and associated end-of-life care after pacemaker or implantable cardioverter-defibrillator deactivation. Am J Hosp Palliat Med 2016;33:966-71.

12. Javaid MR, Squirrell S, Farooqi F. Improving rates of implantable cardioverter defibrillator deactivation in end-of-life care. BMJ Open Qual 2018;7:e000254.
13. Benjamin MM, Sorkness CA. Practical and ethical considerations in the management of pacemaker and implantable cardiac defibrillator devices in terminally ill patients. Proc (Bayl Univ Med Cent) 2017;30:157-60.

14. Turner S, Torabi S, Stilos K. Quality dying: an approach to ICD deactivation in the hospital setting. Am J Hosp Palliat Med 2020;37:664-8.

15. Huddle TS, Bailey FA. Pacemaker deactivation: withdrawal of support or active ending of life? Theor Med Bioeth 2012;33:421-33.

16. Young KA, Redfield MM, Strand JJ, Dunlay SM. End-of-life discussions in patients with heart failure. J Card Fail 2017;23:821-5.

17. You JJ, Ducharme A, Maclver J, et al. Barriers to goals of care discussions with patients who have advanced heart failure: results of a multi-centre survey of hospital-based cardiology clinicians. J Card Fail 2017;23:786-93.

18. Hill L, Mcllfatrick S, Taylor BJ, et al. Patient and professional factors that impact the perceived likelihood and confidence of healthcare professionals to discuss implantable cardioverter defibrillator deactivation in advanced heart failure: results from an international factorial survey. J Cardiovasc Nurs 2018;33:527-35.

19. Bradley AJ, Marks AD. Clinician attitudes regarding ICD deactivation in DNR/DNI patients. J Hosp Med 2017;12:498-502.

20. Silverman HJ, Gordon-Lipkin E, Caputo L, et al. Perceived comfort level of medical students and residents in handling clinical ethics issues. J Med Ethics 2013;39:55-8.

21. Pauls MA, Ackroyd-Stolarz S. Identifying bioethics learning needs: a survey of Canadian emergency medicine residents. Acad Emerg Med 2006;13:645-52.

22. Brady D. Planning for deactivation of implantable cardioverter defibrillators at the end of life in patients with heart failure. Crit Care Nurse 2016;36:24-31.

23. McLennon SM, Miller WR, Amlin K, Chamness AR, Helft PR. Oncology nurses' experiences with prognosis-related communication with patients who have advanced cancer. Nurse Outlook 2013;61:427-36.

[24]. Kramer DB, Gerhardson S, Mueller LA, et al. Just because we can doesn't mean we should: views of nurses on deactivation of pacemakers and implantable cardioverter-defibrillators. J Interven Card Electrophysiol 2011;32:243-52.

25. Padeletti L, Boncinelli L, Brachman J, et al. EHRA Expert Consensus Statement on the management of cardiovascular implantable electronic devices in patients nearing end of life or requesting withdrawal of therapy. Europace 2010;12:1480-9.

26. Stoevelaar R, Brinkman-Stoppelenburg A, van Driel AG, et al. Implantable cardioverter defibrillator deactivation and advance care planning: a focus group study. Heart 2020;106:190-5.

27. Phua J, Nishimura M, Deng Y, et al. Withholding and withdrawal of life-sustaining treatments in intensive care units in Asia. JAMA Intern Med 2015;175:364-72.

28. Lampert R, Hayes DL, Annas GJ, et al. HRS Expert Consensus Statement on the management of cardiovascular implantable electronic devices (CIEDs) in patients nearing end of life or requesting withdrawal of therapy. Heart Rhythm 2010;7:1008-25.

29. Voorheesa J, Reitjens J, Onwuteaka-Philipsen B, et al. Discussing prognosis with terminally ill cancer patients and relatives: a survey of physicians' intentions in seven countries. Patient Educ Couns 2009;77:430-6.

30. Goodlin SJ. Palliative care in congestive heart failure. J Am Coll Cardiol 2009;54:386-96. 
31. Bello NA, Claggett B, Desai AS, et al. Influence of prior heart failure hospitalization on cardiovascular events in patients with reduced and preserved ejection fraction. Circ Heart Fail 2014;7:590-5.

32. Greene SJ, Fonarow GC, Vaduganathan M, et al. The vulnerable phase after hospitalization for heart failure. Nat Rev Cardiol 2015;12:220-9.

33. Steiner JM, Patton KK, Prutkin JM, Kirkpatrick JN. Moral distress at the end of a life: when family and clinicians do not agree on implantable cardioverter-defibrillator deactivation. J Pain Symptom Manage 2018;55:530-4.
34. Choi DY, Wagner MP, Yum B, et al. Improving implantable cardioverter defibrillator deactivation discussions in admitted patients made DNR and comfort care. BMJ Open Qual 2019;8:e000730.

35. Cavanagh CE, Rosman L, Spatz ES, et al. Dying to know: prognosis communication in heart failure. ESC Heart Fail 2020;7:3452-63.

\section{Supplementary Material}

To access the supplementary material accompanying this article, visit CJC Open at https://www.cjcopen.ca/ and at doi:10.1016/j.cjco.2021.03.006. 